\title{
Isodisomy of Chromosome 6 in a Newborn with Methylmalonic Acidemia and Agenesis of Pancreatic Beta Cells Causing Diabetes Mellitus
}

\author{
Marc J. Abramowicz, * Marc Andrien," Etienne Dupont, ${ }^{*}$ Harry Dorchy, ${ }^{5}$ Jasmine Parma, * Laurence Duprez, \\ Fred D. Ledley," Winnie Courtens, ' and Esther Vamos' \\ *Department of Genetics, and ${ }^{\ddagger}$ Department of Immunology and Transfusion, University Hospital Erasme, B-1070 Brussels, Belgium; \\ 'Department of Pediatrics, Queen Fabiola University Children's Hospital, B-1020 Brussels, Belgium; "Departments of Cell Biology and \\ Pediatrics, Baylor College of Medicine, Houston, Texas 77030; and 'Department of Medical Genetics, University Hospital Brugmann, B- \\ 1020 Brussels, Belgium
}

\begin{abstract}
Isodisomy (ID) is a genetic anomaly defined as the inheritance of two copies of the same genetic material from one parent. ID in an ofispring is a rare cause of recessive genetic diseases via inheritance of two copies of a mutated gene from one carrier parent. We studied a newborn female with a mut ${ }^{\circ}$ form of methylmalonic acidemia and complete absence of insulin-producing $\boldsymbol{\beta}$ cells in otherwise normal-appearing pancreatic islets, causing insulin-dependent diabetes mellitus. The patient died 2 wk after birth. Serotyping of the HLA antigens, DNA typing of $H L A-B$ and $H L A$ class II loci, study of polymorphic DNA markers of chromosome 6, and cytogenetic analysis demonstrated paternal ID, involving at least a 25-centiMorgan portion of the chromosome pair that encompasses the MHC. ID probably caused methylmalonic acidemia by duplication of a mutated allele of the corresponding gene on the chromosome 6 inherited from the father. It is also very likely that ID was etiologically related to the agenesis of $\beta$ cells and consequent insulindependent diabetes mellitus in our patient. We thus speculate on the existence of a gene on chromosome 6 involved in $\beta$ cell differentiation. ( $J$. Clin. Invest. 1994. 94:418-421.) Key words: congenital diabetes mellitus - human leukocyte antigen • isodisomy • methylmalonic acidemia • uniparental disomy
\end{abstract}

\section{Introduction}

Uniparental disomy (UPD) ${ }^{1}$ is a newly recognized genetic anomaly, defined as the inheritance of both copies of genetic

Address correspondence to Marc J. Abramowicz, M.D., Ph.D., Department of Genetics, University Hospital Erasme, 808, Route de Lennik, B-1070 Brussels, Belgium.

Received for publication 14 January 1994 and in revised form 4 April 1994.

1. Abbreviations used in this paper: $\mathrm{cM}$, centiMorgan; ID, isodisomy; IDDM, insulin-dependent diabetes mellitus; MMA, methylmalonic acidemia; MUT, methylmalonyl coenzyme A mutase; UPD, uniparental disomy.

J. Clin. Invest.

(c) The American Society for Clinical Investigation, Inc. 0021-9738/94/07/0418/04 \$2.00

Volume 94, July 1994, 418-421 material from one parent (1). Two subtypes of UPD can be recognized by molecular analysis: heterodisomy, defined as the inheritance of both chromosomes from one parental pair, and isodisomy (ID), defined as the inheritance of two copies of the same chromosome from one parent. UPD can cause disease if it affects a gene showing genomic imprinting, i.e., a gene whose expression depends on parental origin. ID will further result in functional reduction to hemizygosity and can thus cause a recessive disease to occur in the offspring of one carrier parent, even in the absence of genomic imprinting. Cases of UPD affecting various chromosomes have been described in association with disease (2). One case of ID of chromosome 6 has been reported in a patient with complement $\mathrm{C} 4$ deficiency (3).

Methylmalonic acidemia (MMA) is a rare inborn error of metabolism transmitted as an autosomal recessive trait (4). The mut ${ }^{\circ}$ form of MMA is due to a defect in the $M U T$ gene encoding the methylmalonyl coenzyme A mutase apoenzyme (5). The MUT locus has been mapped on the short arm of chromosome $6(6 \mathrm{p} 21)$ and shows genetic linkage to the $\operatorname{MHC}(5,6)$. Several other disease genes are known to lie in the vicinity of the HLA complex, including the gene of one form of spinocerebellar ataxia, SCA1 (7).

Permanent insulin-dependent diabetes mellitus (IDDM) is very rare in the neonatal period. So far, 31 well-documented cases have been published $(8,9)$. Its pathogenesis is unknown in two-thirds of the cases. A very early presentation of autoimmune destruction, which is a more common cause of IDDM, has never been irrefutably demonstrated. Rare causes such as aplasia of the pancreas and congenital absence of the islets of Langerhans have been reported. Isolated absence of the $\beta$ cells has been shown in one case.

We reported recently on a newborn with congenital absence of insulin-producing cells and associated methylmalonyl coenzyme A mutase apoenzyme defect (9). We now show, using molecular techniques, that this patient had paternal ID for at least a 25-centiMorgan (cM) portion of chromosome 6 encompassing the $H L A$ loci.

\section{Methods}

Patient. A detailed clinical description has been reported elsewhere (9). Briefly, IDDM was discovered shortly after birth in a small for gestational age female born to healthy, nonconsanguinous Caucasian parents. Because of persisting acidosis after stabilization of glycemia, an inborn error of metabolism was suspected, and MMA was diagnosed. The 
child died on day 16 in spite of therapy. Enzymatic studies on cultured fibroblasts from a skin biopsy specimen were diagnostic of a mut ${ }^{\circ}$ form of MMA. Postmortem studies showed a grossly normal pancreas. Immunohistochemistry, electron microscopy, and in situ hybridization studies using insulin mRNA probes failed to detect any insulin-producing cells in otherwise apparently normal islets. HLA typing and DNA analyses were then undertaken in the propositus and the family. The infant did not demonstrate the presence of autoantibodies to islet cells or insulin.

HLA typing. Serological HLA phenotyping was performed using the fluorochromasia cytotoxicity test (10) on peripheral blood mononuclear cells from the parents and grandparents, on cultured skin fibroblasts from the patient, and on amniotic cells from a second fetus. Before typing, skin fibroblasts and amniotic cells were incubated with recombinant $\gamma$-interferon (Boehringer Mannheim GmbH, Mannheim, Germany) and tumor necrosis factor- $\alpha$ (generous gift from Pr. W. Fiers, Laboratory of Molecular Biology, University of Ghent, Belgium) to enhance class I molecule expression (11).

Molecular genetics. All DNA manipulations were done using standard procedures (12). DNA was extracted from cultured skin fibroblasts of the patient, from peripheral leukocytes of the parents, and from amniotic cells of the second fetus. The B*35, B*0801, and B*51 DNA typing was performed as described (13), except that the $3^{\prime}$ primer used for $B * 51$ typing was $B * 515^{\prime}$-ggttgtagtagcggagcgcga- $3{ }^{\prime}$. Primers and PCR conditions for the $B * 44$ subtyping were as follows (14): primer B *44-P1: 5'-gggccagggtctcacatca-3'; primer B *44-P4: 5'-cactgcccctggtacccgc- $3^{\prime} ;$ the PCR reaction yielded a 298-base pair product and was performed as described in reference 13 , except that the annealing temperature was $60^{\circ} \mathrm{C}$ and final $\mathrm{MgCl}_{2}$ concentration was $1.25 \mathrm{mM}$. Hybridization was performed at $50^{\circ} \mathrm{C}$ with SSO-D156 probe whose sequence is $5^{\prime}$-ctctgtcctgctccgccac-3'. SSO-D156 recognizes the B*4401/02 subtypes and not the B*4403 subtype. HLA class II alleles of the DRB1, DRB3, DRB4, DRB5, DQA1, DQB1, and DPB1 genes were defined using primers and oligonucleotide probes described (15).

The B-12 dinucleotide repeat polymorphism at the TCTE1 locus was studied with the B-12 primers as described in reference 6 . The D6S255 dinucleotide repeat polymorphic locus was studied as described in reference 16 . The polymorphic trinucleotide repeat tract of the SCAI gene was studied as described in reference 7 . The HindIII polymorphic restriction site of exon III of the MUT gene was studied as described in reference 5.

Chromosome analysis. Standard G-banding was performed on chromosomes from peripheral blood mononuclear cells of the patient and her parents and on fibroblasts cultured from a skin biopsy specimen of the patient. All manipulations were done according to standard procedures (17).

\section{Results}

HLA class I serotyping performed on the fibroblasts from the patient showed apparent homozygosity and lack of inheritance of maternal alleles. The patient was A11, B44 (Bw4), Cw5. The mother was A3, A11, B35 (Bw6), Cw4, DR1, DR14, DQ5, and the father was A1, A11, B8, B44 (Bw4, Bw6), Cw5, Cw7, DR4, DR15, DQ6, DQ7. Homozygosity of maternal HLA-B35 antigens was confirmed by typing the maternal grandparents. Haplotypes deduced from segregation analysis in this family are shown in Fig. 1. These results were confirmed by DNA analyses of the $H L A-B$ and $H L A$ class II genes (Table I).

Molecular study of the polymorphic trinucleotide repeat tract of the $S C A 1$ gene were as follows (the alleles are labeled arbitrarily according to sizes ): mother 2,4 ; father 1,3 ; patient 1, 1. Study of the polymorphic HindIII restriction site in exon III of the MUT gene showed that the patient was homozygous for an allele shared by his parents, and study of two other

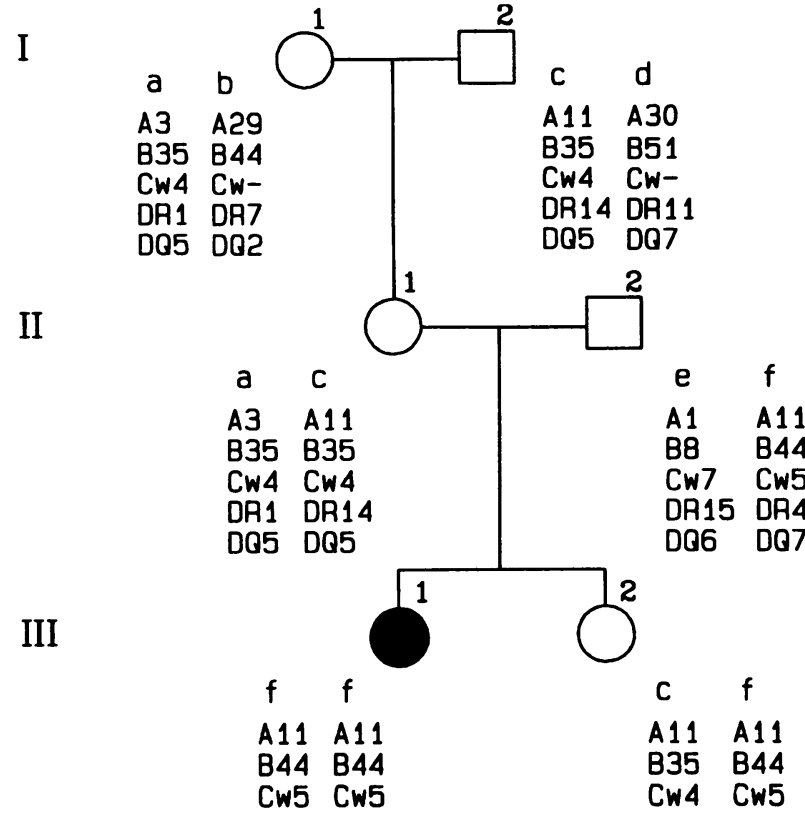

Figure 1. Serological typing of HLA antigens in the family. Squares denote male family members, and circles denote female family members. The patient (III-1) is represented by a solid symbol. Serological typing of the HLA-A, -B, -C, -DR, and -DQ antigens is indicated by upper-case letters and numbers. The haplotypes are deduced from segregation analysis and are labeled arbitrarily in lower-case letters.

polymorphic loci on chromosome 6 gave similar results, summarized in Fig. 2.

Serotyping and DNA analyses on a chorionic villus sample from a subsequent pregnancy showed normal inheritance of maternal and paternal HLA alleles, and assay of methylmalonic acid in amniotic fluid was normal. This pregnancy resulted in the birth of a healthy child (Fig. 1).

Table I. DNA Typing of HLA Genes

\begin{tabular}{|c|c|c|}
\hline Haplotype & Class I & Class II \\
\hline a & B*3501-08 & $\begin{array}{l}\text { DRB } 1 * 0101-\mathrm{DQA} 1 * 0101-\mathrm{DQB} 1 * 0501- \\
\text { DPB } 1 * 0402\end{array}$ \\
\hline b & $B * 4403$ & $\begin{array}{l}\text { DRB } 1 * 0701 / 02-\mathrm{DRB} 4 * 0101-\mathrm{DQA} 1 * 0201- \\
\mathrm{DQB} 1 * 0201-\mathrm{DPB} 1 * 1101\end{array}$ \\
\hline c & B*3501-08 & $\begin{array}{l}\text { DRB } 1 * 1401-\mathrm{DRB} 3 * 0201 / 02-\mathrm{DQA} 1 * 0101- \\
\mathrm{DQB} 1 * 05031-\mathrm{DPB} 1 * 0601\end{array}$ \\
\hline d & B*5101-04 & $\begin{array}{l}\text { DRB } 1 * 1101 / 04-\mathrm{DRB} 3 * 0202-\mathrm{DQA} 1 * 0501- \\
\mathrm{DQB} 1 * 0301-\mathrm{DPB} 1 * 0401\end{array}$ \\
\hline e & B*0801 & $\begin{array}{l}\text { DRB } 1 * 1501 / 03-\mathrm{DRB} 5 * 0101-\mathrm{DQA} 1 * 0101- \\
\mathrm{DQB} 1 * 05031-\mathrm{DPB} 1 * 0401\end{array}$ \\
\hline f & B*4401-02 & $\begin{array}{l}\text { DRB } 1 * 0401-\mathrm{DRB} 4 * 0101-\mathrm{DQA} 1 * 0301 / 02 \text { - } \\
\text { DQB } 1 * 0301-\mathrm{DPB} 1 * 0401\end{array}$ \\
\hline
\end{tabular}

$H L A$ alleles were typed by molecular analysis as described in Methods. Haplotypes are deduced from segregation analysis of the alleles in the family and are labeled arbitrarily in lower-case letters as in Fig. 1. 
II

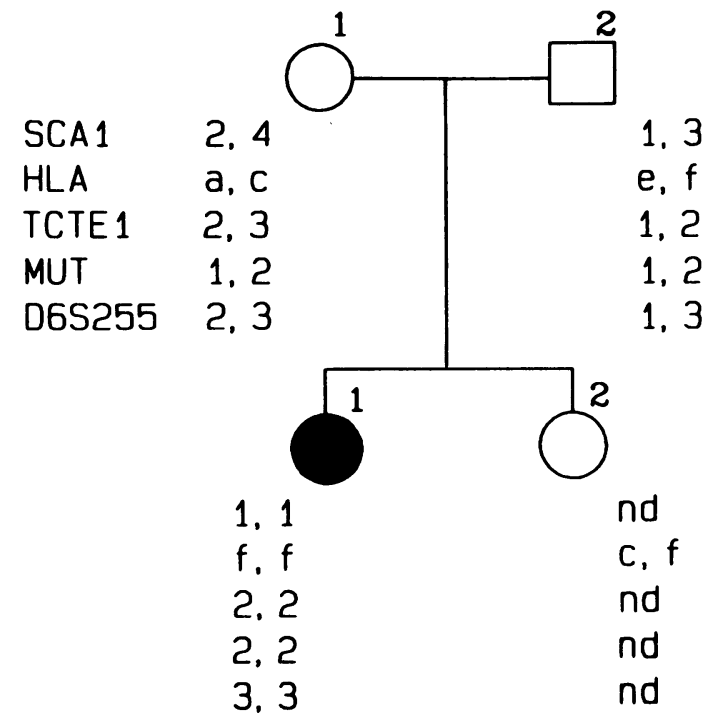

Figure 2. DNA polymorphisms on chromosome 6. Squares denote male family members, and circles denote female family members. The patient (III-1) is represented by a solid symbol. The alleles at the SCA1, TCTE1, MUT, and D6S255 loci were identified by molecular analysis and are labeled arbitrarily in arabic numbers. The HLA haplotypes are represented arbitrarily in lower-case letters as in Fig. 1 and Table I. $n d$, not determined. The order of the loci on chromosome 6 is as follows: SCA1-HLA-TCTE1-MUT-centromere-d6S255.

\section{Discussion}

In this newborn with MMA and IDDM related to congenital absence of insulin cells, we investigated the MHC because of its linkage to the MUT locus and its association with IDDM (18). The segregation study showed apparent absence of inheritance of maternal alleles and homozygosity for paternal alleles (Fig. 1). Such a pattern could have resulted from a vast deletion encompassing the MHC and the MUT locus on the short arm of the maternally inherited chromosome 6, with the father being a carrier for a mutated $M U T$ allele on the chromosome he transmitted to the patient. The $M U T$ gene is widely separated from the $H L A$ genes on chromosome 6 , with a genetic distance larger than $25 \mathrm{cM}(6)$. Therefore, a deletion removing the $H L A$ and the MUT genes would be easily detectable on chromosomes examined at the 400-band resolution level (17). Cytogenetic analysis clearly showed a normal karyotype in our patient and in her parents. This finding could still be explained by the coincidental occurrence of MMA due to inheritance of a mutated MUT allele from each parent and a complete deletion of the $H L A$ cluster on the maternally inherited chromosome. A complete deletion of the MHC with normal high-resolution cytogenetic analysis has been reported in a case of 21-hydroxylase deficiency (19). The findings in the present case, however, were suggestive of paternal ID implicating the $H L A$ and the $M U T$ loci. Paternal ID was confirmed by studying the trinucleotide repeat polymorphism of the $S C A l$ gene, which was totally informative in this family and displayed lack of inheritance of either maternal alleles. The $S C A 1$ gene lies $\sim 20 \mathrm{cM}$ telomeric to the MHC, and the MHC itself covers $\sim 5 \mathrm{cM}(20)$. A deletion of the SCAI and HLA loci would thus cover $25 \mathrm{cM}$ and would be easily detectable on standard cytogenetic analysis (17). There- fore, lack of inheritance of maternal $H L A$ and $S C A 1$ alleles with normal cytogenetic analysis could only be explained by paternal UPD, and detection of only one paternal allele at each locus demonstrated paternal ID. Results of other polymorphic loci analyses on chromosome 6 are shown in Fig. 2. These results suggest involvement of the entire chromosome pair by paternal ID, but do not demonstrate it because of partial informativity in this family. The TCTE1 locus lies between the HLA and $M U T$ loci at $\sim 24 \mathrm{cM}$ from the MHC (6); the D6S255 locus maps to the long arm of chromosome 6 (6q24-25.1) (16).

Taking these results together, MMA in our patient is best explained by reduction to hemizygosity for a mutated $M U T$ allele on the paternally inherited chromosome 6 . The absence of a reliable noninvasive test to assess the carrier status for MMA in the parents presently makes it difficult to prove this hypothesis. Nonetheless, it appears highly unlikely that in this patient homozygosity for linked loci on chromosome 6, i.e., mutated MUT alleles and paternal HLA alleles, would be unrelated chance events.

The occurrence of congenital IDDM in a child with a genetic anomaly of chromosome 6 may be merely coincidental, but this finding is intriguing. Pathologic examination showed complete absence of insulin-producing cells in otherwise normal-appearing pancreatic islets. It is also noteworthy that the $H L A$ $D Q$ genotype of the patient, DQA1 *0301/0302-DQB1 *0301, is not associated with a significantly increased risk for autoimmune IDDM in our population (18), and no antibodies were detected against insulin nor pancreatic islets. Thus, a very early insulitis with complete destruction of the $\beta$ cells in utero is a very unlikely explanation for IDDM in this case. Conversely, our observations are entirely consistent with $\beta$ cell agenesis. Interestingly, the congenital absence of $\beta$ cells in association with a genetic abnormality of the MHC is reminiscent of observations in transgenic mice models with abnormal expression of histocompatibility antigens in the pancreatic islet cells. In these experiments, $\beta$ cell-targeted ectopic expression of class II antigens (21) or overexpression of a class I antigen (22) led to IDDM with depletion of insulin-producing cells and without signs of insulitis. However, it is hazardous to speculate that ID altered the prenatal expression of the $H L A$ genes specifically in the developing islets as to result in $\beta$ cell agenesis similar to the transgenic models. Furthermore, congenital IDDM was not observed in the patient previously described to have paternal ID of the MHC (3). Still, it should be interesting to investigate further cases of congenital IDDM for UPD of HLA genes.

Alternatively, our observation might point to a developmental gene on chromosome 6 , implicated in $\beta$ cell differentiation. Loss of function of such a putative gene might result from the duplication of a mutated allele carried by the father; it is tempting to speculate that a single mutational event (deletion, rearrangement), too small to be detected cytogenetically, would be responsible for both the mut ${ }^{\circ}$ phenotype and the silencing of a gene required for $\beta$ cell development. Alternatively, genomic imprinting of this putative gene could be responsible if only the maternal alleles are functionally expressed. This situation is exemplified in cases of Angelman and Beckwith-Wiedemann syndromes (2), but is unlikely in our case, as congenital IDDM was not observed in the patient previously described to have paternal ID of the $H L A$ region (3). Future work will aim at analyzing the MUT locus region in search of the mutation responsible for MMA. Were a submicroscopic deletion or re- 
arrangement detected, this approach might eventually lead to the identification of a $\beta$ cell developmental gene within or at its borders.

\section{Acknowledgments}

We thank D. Blum for active support and interest. Providing of the primers and PCR conditions for $H L A-B * 44$ subtyping by J.-M. Tiercy (Geneva, Switzerland) is deeply acknowledged. We thank H. Y. Zoghbi (Houston, TX) for useful information and probes, and G. Vassart for continuous support and informative discussions.

F. D. Ledley was supported by National Institutes of Health grant R01-HD24186.

\section{References}

1. Engel, E. 1980. A new genetic concept: uniparental disomy and its potential effect, isodisomy. Am. J. Med. Genet. 6:137-143.

2. Engel, E. 1993. Uniparental disomy revisited: the first twelve years. Am. J. Hum. Genet. 46:670-674.

3. Welch, T. R., L. S. Beischel, E. Choi, K. Balakrishnan, and N. A. Bishof. 1990. Uniparental isodisomy 6 associated with deficiency of the fourth component of complement. J. Clin. Invest. 86:675-678.

4. Rosenberg, L. E., and W. A. Fenton. 1989. Disorders of propionate and methylmalonate metabolism. In The Metabolic Basis of Inherited Diseases. 6th ed. C. R. Scriver, A. L. Beaudet, W. S. Sly, and D. Valle, editors. McGraw-Hill Inc., New York. 821-844.

5. Ledley, F. D., M. R. Lumetta, H. Y. Zoghbi, P. Van Tuinen, S. A. Ledbetter and D. H. Ledbetter. 1988. Mapping of human methylmalonyl CoA mutase (MUT) locus on chromosome 6. Am. J. Hum. Genet. 42:839-846.

6. Kwiatkowski, T. J., A. L. Beaudet, B. J. Trask, and H. Y. Zoghbi. 1991. Linkage mapping and fluorescence in situ hybridization of TCTE1 on human chromosome 6p: analysis of dinucleotide polymorphisms on native gels. Genomics. 10:921-926.

7. Orr, H. T., M.-Y. Chung, S. Banfi, T. J. Kwiatkowski, A. Serviado, A. L. Beaudet, A. E. McCall, L. A. Duvick, L. P. W. Ranum, and H. Y. Zoghbi. 1993 Expansion of an unstable trinucleotide CAG repeat in spinocerebellar ataxia type 1. Nature Genetics. 4:221-226.

8. Dorchy, H., H. Ooms, and H. Loeb. 1975. Permanent neonatal diabetes mellitus: a case report with plasma insulin studies. Eur. J. Pediatr. 118:271-281.

9. Blum, D., H. Dorchy, T. Moureaux, E. Vamos, Y. Mardens, A. Kumps, C. De Prez, P. Heimann, B. Fowler, R. Baumgartner, et al. 1993. Congenital absence of insulin cells in a neonate with diabetes mellitus and mutase-deficient methylmalonic acidemia. Diabetologia. 36:352-357.

10. Bodmer, W., M. Tripp, and J. Bodmer. 1967. Application of a fluorochromatic cytotoxicity assay to human leukocyte typing. In Histocompatibility Testing. E. S. Curtoni, P. L. Mattiuz, and R. M. Tosi, editors. Munksgaard International Publishers Ltd., Copenhagen, Denmark. 341-350.

11. Pfizenmaier, K., P. Scheurich, C. Schluter, and M. Kronke. 1987. Tumor necrosis factor enhances HLA-A,B,C and HLA-DR gene expression in human tumor cells. J. Immunol. 138:975-980.

12. Sambrook, J., E. F. Fritsch, and T. Maniatis. 1989. Molecular Cloning: A Laboratory Manual. Cold Spring Harbor Laboratory, Cold Spring Harbor, NY. 9.16-9.23.

13. Andrien, M., J.-M. Tiercy, V. Defleur, C. Bouillenne, M. Toungouz, M. Jeannet, and E. Dupont. 1993. HLA-B locus DNA typing: detection of B*7801 and seven additional alleles by Bw6-specific exon 2 amplification. Tissue Antigens. 42:480-487.

14. Tiercy, J.-M., N. Djavad, N. Rufer, D. Speiser, M. Jeannet, and E. Roosnek. 1994. Oligotyping of HLA-A2-, A3-, and B44-subtypes: detection of subtypeincompatibilities between patients and their serologically matched unrelated bone marrow donors. Hum. Immunol. In press.

15. Kimura, A., and T. Sasasuki. 1992. DNA component: eleventh international histocompatibility workshop reference protocol for the HLA DNA typing techniques. In HLA 1991. K. Tsuji, M. Aizawa, and T. Sasazuki, editors. Oxford University Press, Oxford. 397-453.

16. Wilkie, P. J., M. H. Polymeropoulos, J. M. Trent, K. W. Small, and J. L. Weber. 1993. Genetic and physical map of 11 short tandem repeat polymorphisms on human chromosome 6. Genomics. 15:225-227.

17. Ledbetter, D. H., and W. K. Cavenee. 1989. Molecular Cytogenetics. In The Metabolic Basis of Inherited Diseases, 6th ed. C. R. Scriver, A. L. Beaudet, W. S. Sly, and D. Valle, editors. McGraw-Hill Inc., New York. 343-371.

18. Thorsby, E., and K. S. Ronningen. 1993. Particular HLA-DQ molecules play a dominant role in determining susceptibility or resistance to type 1 (insulindependent) diabetes mellitus. Diabetologia. 36:371-377.

19. Hejtmancik, J. F., S. Black, S. Harris, P. A. Ward, C. Callaway, D. Ledbetter, J. Morris, S. H. Leech, and M. S. Pollack. 1992. Congenital 21-hydroxylase deficiency as a new deletion mutation. Hum. Immunol. 35:246-252.

20. Zoghbi, H. Y., C. Jodice, L. Sandkuijl, T. J. Kwiatkowski, A. E. McCall, S. A. Huntoon, P. Lulli, M. Spadaro, M. Litt, H. M. Cann, et al. 1991. The gene for autosomal dominant spinocerebellar ataxia (SCA1) maps telomeric to the HLA complex and is closely linked to the D6S89 locus in three large kindreds. Am. J. Hum. Genet. 49:23-30.

21. Sarvetnick, N., D. Liggitt, S. L. Pitts, S. E. Hansen, and T. A. Stewart. 1988. Insulin-dependent diabetes mellitus induced in transgenic mice by ectopic expression of class II MHC and interferon gamma. Cell. 52:773-782.

22. Allison, J., I. L. Campbell, G. Morahan, T. E. Mandel, L. C. Harrison, and J. F. A. P. Miller. 1988. Diabetes in transgenic mice resulting from overexpression of class I histocompatibility molecules in pancreatic $\beta$ cells. Nature (Lond.). 333:529-533. 